\title{
RELIEFNE OBLIKE KOT GEODIVERZITETA (GEOMORFOLOŠKA NARAVNA DEDIŠČINA)
}

\author{
Bojan Erhartič \\ Geografski inštitut Antona Melika ZRC SAZU \\ Gosposka I3, SI-I000 Ljubljana, Slovenija \\ e-mail: bojaner@zrc-sazu.si
}

Izvirni znanstveni članek

Cobiss 1.01

\section{Izvleček}

Prispevek skuša osvetliti različne vrednote reliefnih oblik kot sestavnega dela geomorfološke naravne dediščine ter pomagati pri uveljavljanju termina geodiverziteta v Sloveniji. Članek predstavi razloge, zakaj vrednotiti geodiverziteto, katerim sledi razprava o specifičnih vidikih naravnih vrednot: intrinzičnih, kulturnih, estetskih, socialno-ekonomskih, funkcijskih, geosistemskih, znanstvenoraziskovalnih in izobraževalnih.

Ključne besede: geografija, geomorfologija, geodiverziteta, reliefna oblika, naravna vrednota, geomorfološka naravna vrednota.

\section{LANDFORMS AS GEODIVERSITY (GEOMORPHOLOGICAL NATURAL HERITAGE)}

\begin{abstract}
This paper highlights different values of the landforms as part of geomorphological heritage and helps to put forward the term geodiversity in Slovenia. The article provides reasons to value geodiversity and is followed by a discussion of the specific types of values: intrinsic, cultural, aesthetic, socio-economic, functional, geosystem, research and educational.
\end{abstract}

Key words: geography, geomorphology, geodiversity, landform, natural heritage, geomorphological natural heritage/geomorphosite. 


\section{UVOD}

Po mnenju Sacksa (2002) v svetu globalizacije ni dovolj strpnost do razlik, čeprav bi morali različnost spoštovati, naj gre za versko, kulturno ali naravno. V zadnjem desetletju in pol je bil trend k opisovanju in vrednotenju diverzitete najmočnejši na področju biologije, kjer je naraščala zaskrbljenost zaradi izumiranja vrst in izgube njihovih habitatov, kar je vodilo do nekaterih mednarodnih sporazumov. Od konference v Riu (1992) je bilo precej pozornosti namenjene varovanju in povečevanju biodiverzitete na vseh nivojih človekove družbe.

Čeprav se varstvo geološke in geomorfološke dediščine ponekod prakticira že več kot stoletje, so danes številnenaravovarstvene organizaciješe vednousmerjene predvsemv varstvo vrst in njihovih habitatov. Pristojne službe poudarjajo potrebo po varstvu biodiverzitete, ob tem pa pozabljajo na relief in matično podlago - na geološke, geomorfološke in hidrološke pojave, ki so dali osnovo za življenje na Zemlji.

Geologi in geomorfologi, vpeti v varstvo narave, so začeli v devetdesetih letih prejšnjega stoletja uporabljati termin geodiverziteta za opisovanje pestrosti nežive narave.

Popularnost biodiverzitete glede na geodiverziteto lahko prikažemo tudi s pomočjo spletnega brskalnika. Če v Google vtipkamo besedo »biodiversity«, dobimo kar 29 milijonov zadetkov, medtem ko besedi »geodiversity« ustreza le okoli 116.000 zadetkov (stanje 1. 7. 2007).

Prispevek skuša osvetliti različne vrednosti reliefnih oblik kot sestavnega dela geomorfološke naravne dediščine ter pomagati pri uveljavljanju termina geodiverziteta v Sloveniji. Podana je potreba po celovitem pristopu $\mathrm{k}$ varstvu narave in upravljanju $\mathrm{z}$ okoljem ter poudarjena vloga geografije in geomorfologije kot disciplin, ki sta na področju ohranjanja narave in varstva naravne dediščine nekoliko zaspali.

Namen sestavka je s pomočjo slovenske zakonodaje prikazati stanje in metodološke zaplete pri ocenjevanju neživih sestavin narave, ki bodo podprli prizadevanja za natančnejše vrednotenje, popularizacijo in interpretacijo geomorfološke dediščine na Slovenskem.

\section{GEODIVERZITETA IN NARAVNE VREDNOTE}

Kdaj in kdo je prvi začel uporabljati pojem geodiverziteta - kaže, da je skovanka najprej vzklila med tasmanskimi geomorfologi (Gray, 2004) - pravzaprav ni bistveno; pomembno je razumevanje oziroma obseg pojma. Poročilo Australian Heritage Commission iz leta 2002 jo definira kot »naravni razpon (pestrost) geoloških (kamnine, minerali, fosili), geomorfoloških (reliefne oblike, procesi) in pedoloških značilnosti. Geodiverziteta zajema njihovo zbiranje, (so)odvisnost, lastništvo, interpretacijo in sistematizacijo.« (Medmrežje)

Definicija angleških strokovnjakov je podobna, a vsebuje tudi ljudi in kulturo: »Je povezava med ljudmi, pokrajino in kulturo; je raznolikost geoloških in geomorfoloških okolij, pojavov in procesov, ki so oblikovali (neko) pokrajino, relief, kamnine, skale, minerale, fosile in prst, ki predstavljajo okvir za življenje na Zemlji.« (Gray 2004, 7) Preprostejša definicija se lahko glasi: geodiverziteta je pestrost in kompleksna povezanost geoloških in geomorfoloških pojavov in procesov ter prsti na določenem območju. Še enostavneje jo definiramo kot pestrost nežive narave. 
Zakon o ohranjanju narave (Uradni list RS 96/2004) geodiverzitete ne omenja, a opredeljuje nekatere sestavine narave, ki ustrezajo terminu. Po njem naravne vrednote obsegajo vso naravno dediščino in so torej deli narave, ki imajo posebne vrednostne lastnosti. To so »zlasti geološki pojavi, minerali in fosili ter njihova nahajališča, površinski in podzemski kraški pojavi, podzemske jame, soteske in tesni ter drugi geomorfološki pojavi, ledeniki in oblike ledeniškega delovanja, izviri, slapovi, brzice, jezera, barja, potoki in reke z obrežji, morska obala, rastlinske in živalske vrste, njihovi izjemni osebki ter njihovi življenjski prostori, ekosistemi, krajina in oblikovana narava.«

Na podlagi Zakona o ohranjanju narave je nastala Uredba o zvrsteh naravnih vrednot (Uradni list RS 52/2002 in 67/2003), ki opredeljuje deset zvrsti naravnih vrednot, od katerih prve štiri, delno tudi zadnja, ustrezajo terminu geodiverziteta: površinska geomorfološka naravna vrednota, podzemeljska geomorfološka, geološka in hidrološka naravna vrednota ter krajinska vrednota. V nadaljevanju sta kot posebni zvrsti dodani še minerali in fosili - kot del pestrosti nežive narave. Gledano širše pa geodiverziteta obsega tudi preostale naravne vrednote, saj daje podlago za biodiverziteto. Stanley (2002) gre pri utemeljevanju še dlje, ko trdi, da je biodiverziteta pravzaprav le del geodiverzitete.

Slika 1: Hudičev stolp v Wyomingu, ZDA-izjemen primer geomorfološke vrednote in prvi naravni spomenik na svetu (od leta 1906) (B. Erhartič)

Figure 1: Devils Tower in Wyoming, USA is an exceptional example of geomorphological heritage and the first national monument in the world (since 1906) (B. Erhartič)

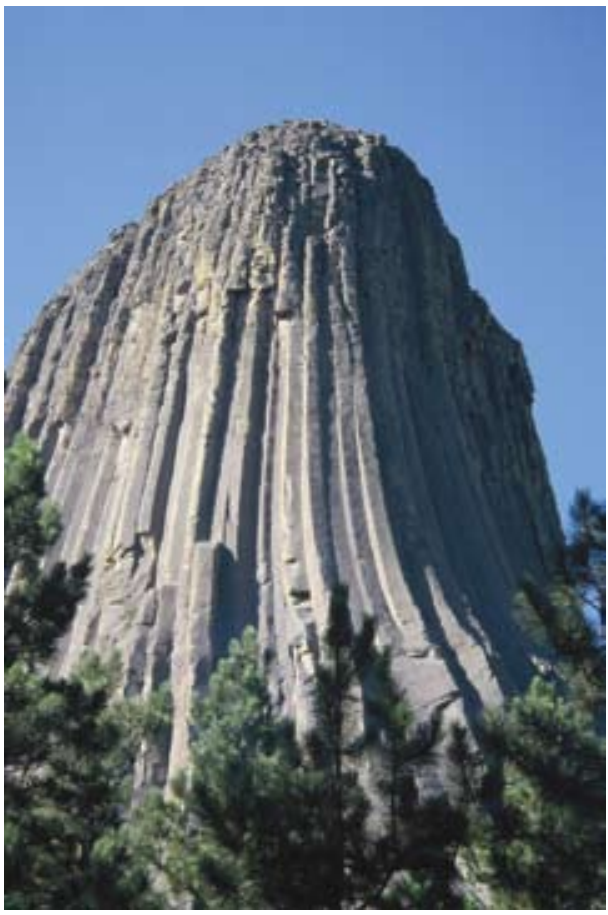


Največjo pestrost pojavnih oblik prav gotovo obsegajo površinske geomorfološke naravne vrednote, ki so po omenjeni uredbi »del narave, ki je z vidika zemeljskega površja izjemen, tipičen, kompleksno povezan, ohranjen, redek, znanstveno-raziskovalno ali pričevalno pomemben in se v naravi pojavlja zlasti kot kraška površinska oblika (žlebič, škraplja, vrtača, uvala, kotlič, udornica, draga, kraško polje, kraški ravnik, kraška planota), ledeniška reliefna oblika (ledeniška morena, krnica, balvan, ledeniška dolina, grbina, prag), rečnodenudacijska oblika (korito, soteska, rečna terasa, poplavna ravnica, vršaj), poligenetska reliefna oblika (vrh, gorski greben, sleme, otok, skalne oblike, kot so naravni most/okno, stena, skalni osamelec) ali obalna reliefna oblika (klif, abrazijski spodmol, terasa).«

Vse geodiverzitete seveda ni potrebno varovati, saj bi to ne nazadnje vodilo k pragmatičnim problemom zaradi potreb družbe po uporabljanju nekaterih naravnih virov. Zato je potrebno (s pravnimi ukrepi) zaščititi najpomembnejše oz. najvrednejše dele nežive narave. Pogosto se pojavljajo problemi s strokovnimi merili določanja oziroma ocenjevanja naravnih vrednot, ki so v Uredbi o spremembah in dopolnitvah uredbe o zvrsteh naravnih vrednot (Uradni list RS 67/2003) precej ohlapna: izjemnost, tipičnost, kompleksna povezanost, ohranjenost, redkost ter ekosistemska, znanstveno raziskovalna ali pričevalna pomembnost.

Razlogov zakaj vrednotiti geodiverziteto je veliko, povzema jih Guthrie (2004):

- $\quad$ ker nas oskrbuje s proizvodi in storitvami;

- $\quad$ ker morajo vlade sprejemati odločitve (zlasti za posege v prostor) skladno s trajnostnim upravljanjem geodiverzitete;

- $\quad$ ker geodiverziteta daje ljudem zadovoljstvo, prinaša blaginjo;

- ker raziskovanje geodiverzitete prispeva k napredku znanosti in industrije;

- ker je pomembna za usposabljanje naravoslovcev (geografov, geomorfologov, geologov);

- $\quad$ ker je učni pripomoček za izobraževanje (učilnica v naravi);

- $\quad$ ker dediščina nima le estetske, kulturne, zgodovinske vrednosti za človeka, temveč vrednost za vsa živa bitja.

\section{VREDNOTENJE GEODIVERZITETE}

Po mnenju Panizze (2003) je glavni razlog za ponovno definiranje nekaterih konceptov geomorfoloških naravnih vrednot, njihovega evidentiranja in vrednotenja obstoječe metodologije predvsem vedno večje zanimanje javnosti - s tem pa tudi potencialno ogrožanje - za geološko in geomorfološko dediščino, ti. geoturizem.

Pot k vrednotenju geomorfoloških naravnih vrednot naj bi bila sledeča (Panizza 2003, 23-25):

- izdelava karte geomorfološke dediščine iz geomorfološke karte (terensko delo, letalski posnetki);

- $\quad$ pripisovanje (atributi!) kvalitativne vrednosti izbrani geomorfološki dediščini glede na stopnjo pomembnosti (znanstvena, kulturna, socialno-ekonomska; lokalnega ali narodnega pomena);

- določitev kvantitativnih vrednosti posamezni geomorfološki dediščini - z namenom 
pravilno ovrednotiti te sestavine okolja, ne samo za medsebojno primerjavo, temveč predvsem za njihovo primerjanje z ostalimi sestavinami okolja.

Predlogov, kako pripisati vrednost različnim elementom geomorfološke dediščine je veliko, tudi znotraj postopkov presoj vplivov na okolje.

Problem vrednotenja narave in naravnih vrednot je v tem, da je - ob upoštevanju vseh meril - praktično nemogoče izključiti subjektivno komponento.

Zmotno je tudi prepričanje nekaterih naravovarstvenih gibanj, da je dobro vse, kar je naravno. Naravni pojavi, kot so naravne nesreče, gotovo niso dobro po človekovi presoji. Človekova odločitev je, ali so naravni pojavi zanj indiferentne, intrinzične ali instrumentalne vrednote. Človek jim torej podeli status (vrednote), ne pa tudi kvalitete. Slednje pridobijo $\mathrm{z}$ vrednotenjem poseben pomen za človeka in družbo - postanejo vrednote, ker jih nekdo tako vrednoti (Kirn 2004, 174-175). Neka reliefna oblika postane geomorfološki vir oziroma geomorfološka naravna vrednota le, če ima tudi socialno komponento, če ji geomorfološka stroka podeli status vrednote.

Slika 2: Delane vrtače pri Marindolu (Bela krajina). Primer geomorfološke naravne vrednote in krajinske vrednote (B. Erhartič)

Figure 2: Worked doline near Marindol (Slovenia). Example of geomorphological natural heritage and landscape value (B. Erhartič)

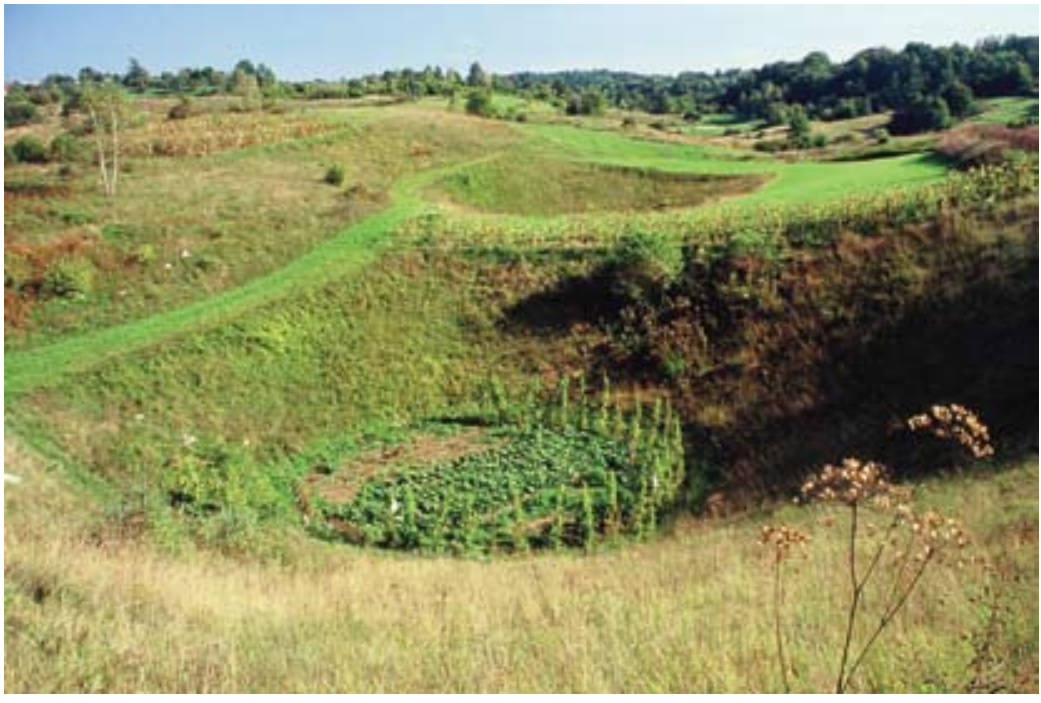

Mnogi avtorji so skušali opredeliti vrednost narave; tako je nastala klasifikacija, ki deli vrednosti narave na naslednje dele - vrednote:

- intrinzične (eksistenčne) vrednote,

- kulturne in estetske vrednote,

- socialno-ekonomske vrednote, 
- funkcijske in geosistemske vrednote,

- znanstvenoraziskovalne in izobraževalne vrednote.

\section{I Intrinzične vrednote}

Intrinzične vrednote se nanašajo na etično prepričanje, da so nekatere stvari (npr. geodiverziteta) vrednote same po sebi in ne zaradi nečesa ali nekoga (Gray 2004; Kirn 2004). Intrinzične vrednote je najtežje določiti in opisati, saj vsebujejo etične in filozofske dimenzije odnosa med naravo in družbo.

Geodiverziteta je tako kot biotska raznolikost intrinzična vrednota, vendar ima za človeka obenem lahko tudi zdravstveno, ekonomsko, spoznavno, izobraževalno ali estetsko (instrumentalno) vrednost. Velja pa seveda tudi obratno: kar je instrumentalno vredno, je lahko, ni pa nujno, tudi intrinzično vredno. Povezanost intrinzične in instrumentalne vrednote lahko ponazorimo na primeru zavarovanih območij. Turistična in rekreacijska funkcija (instrumentalna vrednota) zavarovanih območij kot priložnost za prebivalce zavarovanega območja ne sme ogroziti njihove naravne in kulturne vrednote ter estetske in ekološke vrednosti zavarovanega območja (intrinzične vrednote); na primer masovni turizem (Vršič, Pokljuka, Bohinj) v Triglavskem narodnem parku. Človekova odločitev je, kakšne vrednote bo podelil posameznemu delu narave - geomorfološki dediščini. Če naravnim danostim priznamo intrinzično vrednost, pomeni, da jih ne smemo izrabljati (med »izrabo« sodi tudi turizem, ne le strogo fizično izkoriščanje v smislu kamnoloma gradbenega kamna ali hidroelektrarne) brez ustreznega moralnega razloga, ki odtehta slabost dejanja. Ker živimo od narave, jo moramo nujno tudi strokovno instrumentalno vrednotiti.

\subsection{Kulturne vrednote}

Primerov tovrstne geodiverzitete zaradi kulturnih vrednot ni težko najti kjerkoli po svetu, naj gre za sodobne ali pretekle družbe. Ker so nežive fizične sestavine okolja tako ovrednotene, je seveda smotrno zavarovati celotno pokrajino. Sem lahko spadajo tudi mitološke razlage reliefnih oblik in naravnih pojavov (Poljanska baba), arheološka nahajališča (Potočka Zijalka), zgodovinski kraji (slap Savica) in duhovne vrednote (Triglav, Uluru), saj je geodiverziteta tista, ki je pogojevala oziroma omogočila razvoj človeka.

Reliefne oblike dajejo pečat, identiteto prostoru - ga osmišljajo. Človek se naveže na ta prostor, na pokrajino in se $\mathrm{z}$ njo poistoveti. Umestno je vprašanje, zakaj se mnogi slovenski klubi in društva po svetu imenujejo Triglav, Planica in podobno in zakaj je v domala vsaki dvorani tovrstnih ustanov na glavni steni osrednje dvorane upodobljeno Blejsko jezero $\mathrm{z}$ otokom in Triglavom v ozadju? Geomorfološki pojavi (reliefne oblike) predstavljajo kuliso za naše vsakdanje življenje in vplivajo na splošno počutje in na emocije - navdajajo nas z radostjo in navdihom. Dejstvo je, da odigrata Triglav in Blejsko jezero pomembno vlogo pri identiteti slovenstva. Vsi imamo asociacije na pokrajino, saj sproži odzive, spomine, čustva, ki so zelo osebna. Vsaka pokrajina je nekomu pomembna, naj gre za mestno sosesko ali neokrnjeno naravo. Prav zato je lokalna skupnost tista, ki ceni pokrajino (reliefne oblike) in jo zna tudi ohranjati (Gray 2004). 
Slika 3: Blejsko jezero - portret Slovenije. Preplet naravne in kulturne dediščine, s katero se predstavljamo svetu (B. Erhartič)

Figure 3: Lake Bled-portrait of Slovenia. A combination of natural and cultural heritage that presents us to the world (B. Erhartič)

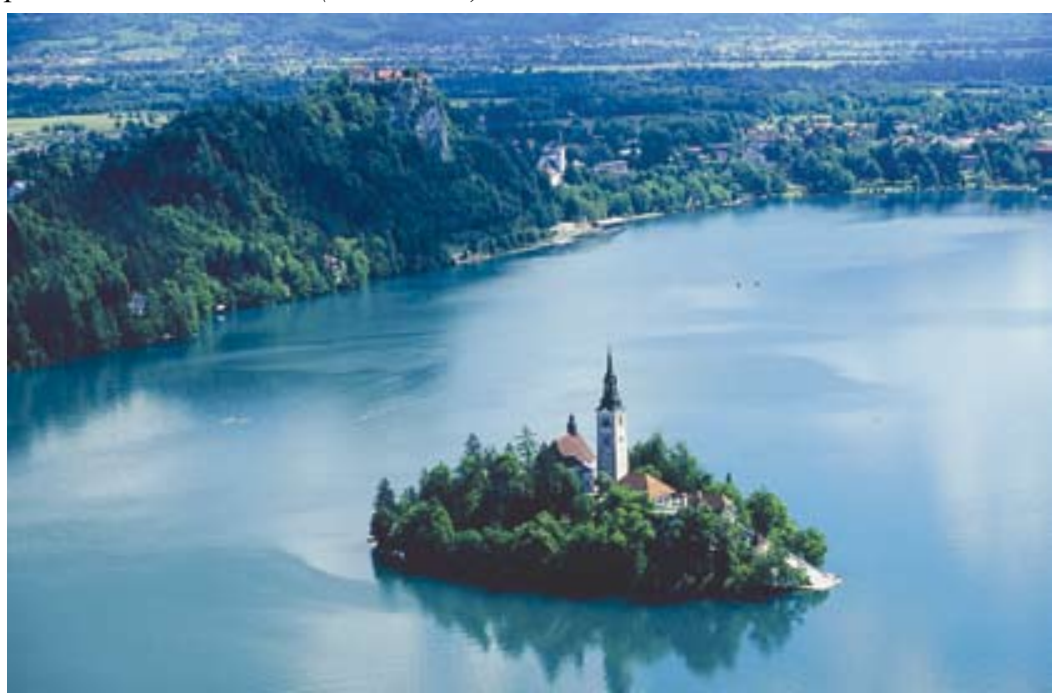

\subsection{Estetske vrednote}

Estetske vrednote geodiverzitete so bolj očitne, saj se nanašajo preprosto na videz vizualni učinek (ter na druga čutila), ki ga daje fizično okolje - reliefne oblike vseh vrst in dimenzij, od gorskih verig in sotesk do vrtač in balvanov. Številni geomorfološki pojavi, ki zagotavljajo prebivalstvu in popotnikom svojevrstno doživetje, imajo v sebi neko vrednost. Človekovo zaznavanje ceni raznolikost, kompleksnost, vzorce in lokalni značaj. Po mnenju Graya $(2004,82)$ je prispevek različnih tipov reliefnih oblik in bogastva površinskih detajlov k popularnosti turističnih območij močno podcenjen. Nekateri avtorji govorijo o »amenity value« (ljubki, privlačnostni vrednoti), kjer prisotnost naravnega pojava (reliefne oblike) izboljša kvaliteto življenja v nematerialnem smislu. Ta splošna vrednost pokrajinske lepote (slikovite pokrajine) je pogosto glavni adut in del oglaševalske kampanje nacionalnih turističnih organizacij. Stacionarni turizem vedno bolj zamenjuje aktivno preživljanje prostega časa (pohodništvo, kolesarstvo, vodni športi). Za takšne rekreativne dejavnosti je potrebna specifična pokrajina oziroma določen relief in reliefne oblike (stene ali balvani za plezanje, reke z zadostnim padcem za rafting ali kanu).

English Nature navaja, da na tako psihično kot fizično zdravje ugodno vpliva bližina oziroma možnost dostopa do zanimivih in pestrih naravnih območij in reliefnih oblik (na primer Šmarna gora, Mariborsko Pohorje) (Gray 2004, 81, 82). Pri tem ni nujno, da gre za izjemen ali redek pojav - tudi tipičnost je eden izmed strokovnih meril vrednotenja geomorfoloških pojavov. Odtod pobuda za ohranjanje pogostih, tipičnih reliefnih oblik (npr. 
šotišč na Škotskem, Finskem ali Poljskem, krasa v Sloveniji ali na Kitajskem) za splošno dobro, ki pogosto izhaja iz lokalne in osebne ocene njene znanstvene in estetske vrednosti.

Reliefne oblike kot element v pokrajini so nedvomno zapostavljene. Vedno spreminjajoča se narava je tista, ki prinaša veliko vizualne interesantnosti in lepote. Estetska vrednost daje tudi ekonomsko vrednost in družbeni status. Tipičen primer najdemo v mnogih družbah, kjer je človek pripravljen plačati vrtoglave vsote za določene pokrajinske atribute, na primer za pogled na morje. Lokacija na vrhu hriba pogosto pomeni več kot samo topografsko višino, saj je marsikje povezana $\mathrm{z}$ višjim socialnim in ekonomskim položajem.

Slika 4: Zajamniki. Najvrednejši deli naravne in kulturne dediščine so zavarovani v Triglavskem narodnem parku (B. Erhartič)

Figure 4: Zajamniki. The most valuable parts of natural and cultural heritage are protected in Triglav National Park (Slovenia) (B. Erhartič)

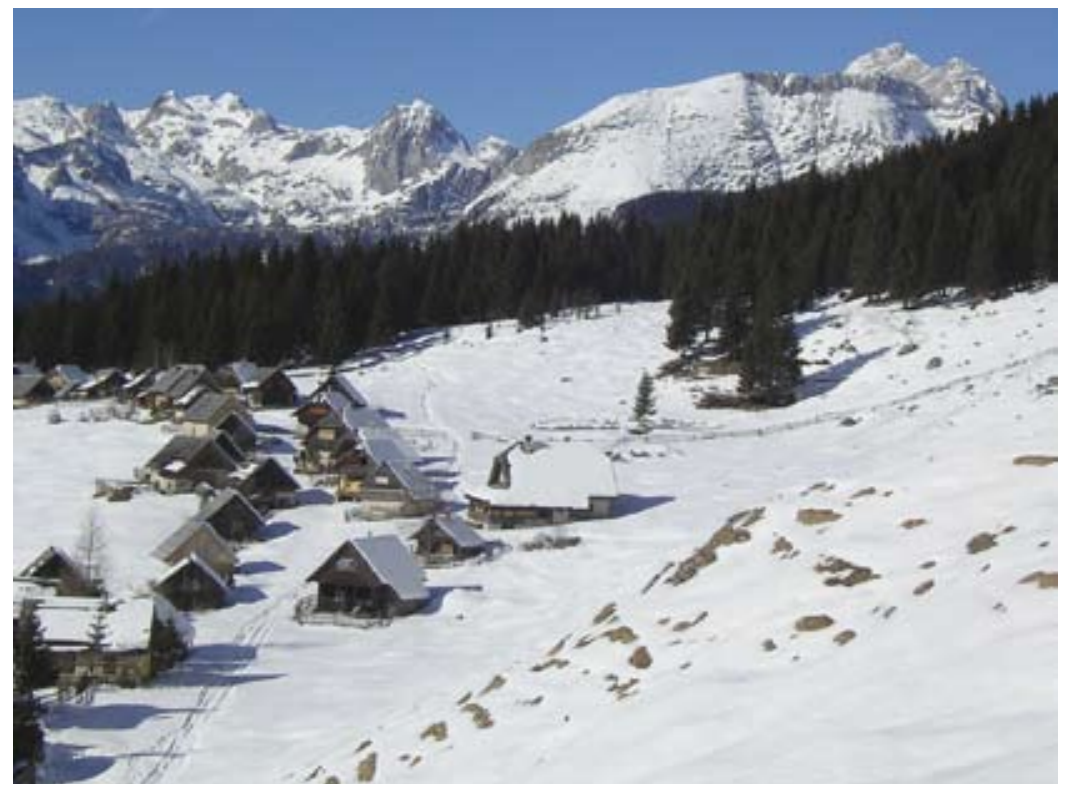

\subsection{Socialno-ekonomske (instrumentalne) vrednote}

Ekonomsko načelo predpostavlja, da varstvo naravnih vrednot ne pomeni samo strošek in omejitve, ampak tudi nove priložnosti, saj je oziroma postaja kakovostno okolje vedno večja vrednota, ki se jo da tudi tržiti.

Gospodarskasferajeposkusilaizpostavitifinančno vrednostvsemokoljskimelementom, vendar ima mnogo geodiverzitete več kot samo teoretično ekonomsko vrednost.

Običajna ekonomska klasifikacija se nanaša na nafto, premog, rudna bogastva, drage kamne in gradbeni material (vse je del geodiverzitete!), povsod pa se zanemarja pomen prsti, reliefnih oblik in drugih naravnih virov. Pri vrednotenju naravne dediščine se pojavijo številne 
težave, ker le-ta ni predmet klasičnih tržnih odnosov - ponudbe in povpraševanja, saj se na trgu ne pojavlja kot blago. Ker dediščina vseeno ima svojo ceno, Winkler (2006) predlaga vrednotenje po koristih, ki jih dediščina nudi. Govorimo o t.i. WTP pristopu (willingness to pay) - koliko je uporabnik pripravljen plačati za dediščino. Iz ekonomske teorije se je razvila vrsta okoljskih tehnik vrednotenja, s katerimi lahko izmerimo ekonomske vrednosti, temelječe na WTP pristopu. Najpomembnejše med njimi so metoda potovalnih stroškov, ki temelji na potovalnih in časovnih stroških, hedonistična in kontingenčna metoda.

Slika 5: Strunjanski klif in Mesečev zaliv. Pritiski na obalo so veliki, zato je naravno ohranjenih reliefnih oblik vse manj (B. Erhartič)

Figure 5: Strunjan cliff and Mesečev zaliv bay, Slovenia. Naturally preserved landforms

diminish because of high impacts on the coast (B. Erhartič)

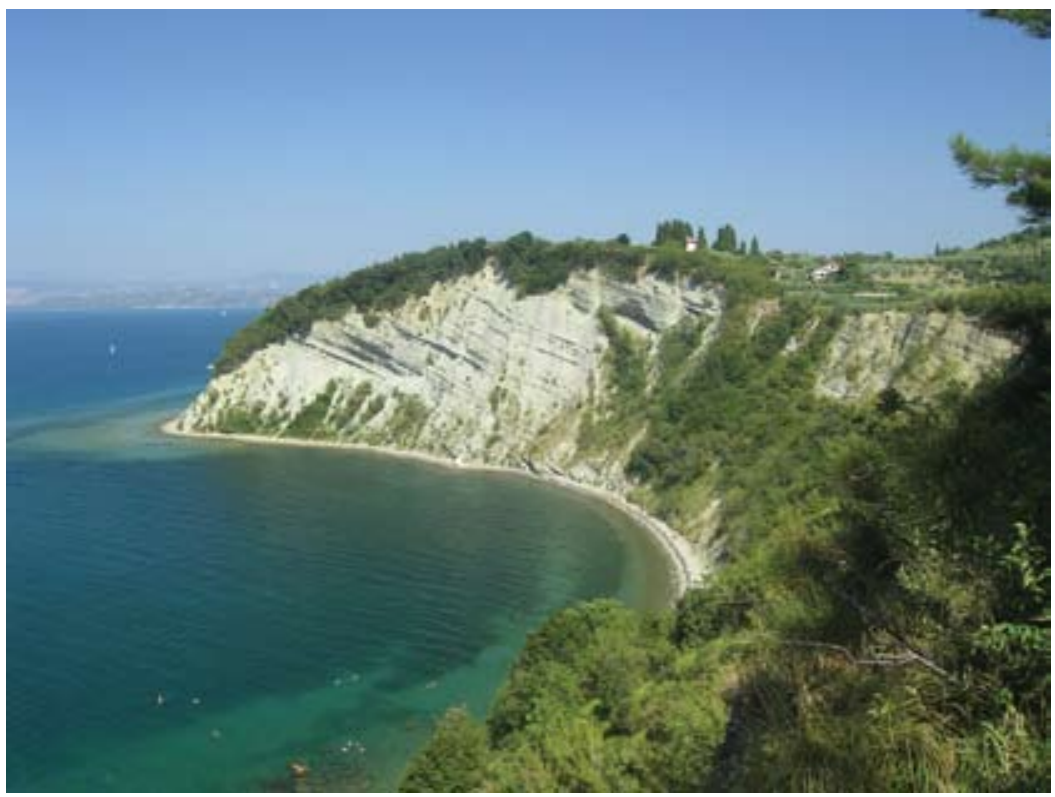

V realnem svetu pogosto pride do prepletanja intrinzičnih in instrumentalnih vrednot. Določeno pokrajino, biotop, reliefno obliko ali živalsko vrsto zaščitimo zaradi njene edinstvenosti, redkosti, ogroženosti, njene ekološke in estetske vrednosti (strokovna merila vrednotenja po slovenski zakonodaji). Zavarovana območja so to postala, ker se je v njih videlo naravne vrednosti ali prepletanje naravnih in kulturnih vrednosti. Pogosto nastane problem, kako naj ljudje živijo na zaščitenem območju, da ne bo to za njih samo breme in ovira. V trženju turistične, rekreacijske funkcije teh območij se je odkrila priložnost za njihove prebivalce. Ta instrumentalna vrednota je omogočena in povezana ravno z intrinzično vrednoto zavarovanega območja. Toda stalno je treba bdeti nad tem, da ohranjamo krhko ravnovesje, da dejavnost, povezana $\mathrm{z}$ instrumentalno vrednoto, ne ogrozi intrinzične vred- 
note (Kirn 2004, 175). Nekaj, kar je intrinzično ne izključuje, da je lahko za človeka hkrati tudi koristno in instrumentalno. Nikakor ne smemo pozabiti na zaposlitvene učinke k lokalni skupnosti, ki jih daje geodiverziteta, zlasti na področju turizma in rabe drugih (neživih) naravnih virov (gradbeni kamen, premog, padec reke za pridobivanje energije). To osvetljuje pomemben prispevek geodiverzitete $\mathrm{k}$ lokalni ekonomiji.

\subsection{Funkcijske vrednote}

Znotraj varstva narave se o njih le redko govori, četudi je vsem jasno, da reliefne oblike, prst, sedimenti, kamnine igrajo pomembno (funkcijsko) vlogo v sistemu okolja, tako fizičnega kot biološkega. Gray $(2004,114)$ loči dve podskupini funkcijskih vrednot:

a) Funkcijska vrednost v smislu zagotavljanja nujno potrebne podlage, habitatov in abiotskih procesov, ki omogočajo fizikalne in ekološke sisteme na površju Zemlje in zato podpirajo biodiverziteto.

b) Utilitaristične (koristoljubne) vrednosti geodiverzitete človeški družbi. Zemeljsko površje predstavlja temelje, na katerih gradimo razvoj in vse človekove aktivnosti. To daje površju funkcionalno in ekonomsko vrednost. Specifična kombinacija reliefnih oblik, kamninske podlage in prsti, naredi nekatera območja primerna na kmetijstvo, druga za izgradnjo letališča ali smučišč, tretja za izkoriščanje hidroenergije. Geodiverziteta torej pogojuje pestrost koristoljubnih funkcionalnih vrednosti različnih delov zemeljskega površja.

K utilitaristični vrednosti geodiverzitete lahko prištevamo tudi tla kot vir oziroma zalogo pitne vode ter njeno veliko samočistilno sposobnost. Čeprav se samočiščenje povsod po svetu vrši s pomočjo istih procesov (adsorbcija, ionske izmenjava, mikrobne dekompozicija, razredčevanje), je učinek le-teh zelo variabilen. Na občutljivost onesnaževanja podtalnice namreč bistveno vpliva debelina krovne plasti (prsti in sedimenta). Tanka krovna plast zagotavlja kaj malo zaščite pred površinskim - zlasti kmetijskim - onesnaževanjem, medtem ko bo debelejša plast gline zelo učinkovita pri preprečevanju onesnaževanja. Vrednost take plasti - dela pestrosti nežive narave - pogosto ni niti (po)znana, kaj šele cenjena (Gray 2004, 116). Nesporno je dejstvo, da nas od svetovne lakote in preživetja na sploh loči nekaj deset centimetrov prsti. Slednja in pa seveda voda, sta ključni za življenje na zemlji.

\subsection{Geosistemska vloga}

Fizikalno okolje igra veliko vlogo $\mathrm{z}$ zagotavljanjem raznolikih okolij, habitatov in substratov, ki dajejo podlago biodiverziteti. Kljub vsemu so nežive sestavine okolja med okoljevarstveniki pogosto zapostavljene. Abiotske sestavine so smatrane kot nespreminjajoča se kulisa, na kateri se razvija ekosistem. Na drugi strani se del vrednosti geomorfoloških vrednot skriva ravno v hitrosti oziroma počasnosti procesov, s katerimi nastajajo. Počasi le prihaja do sprememb, saj se inženirji in ekologi zavedajo nuje po razumevanju procesov in vzorcev fizikalnega okolja, če želijo uspešno upravljati procese in habitate. 
Slika 6: Septarijske konkrecije (Moeraki, Nova Zelandija) so redka oblika geološke in geomorfološke dediščine. V Sloveniji so bile najdene in uničene ob gradnji avtoceste pri Šentilju (B. Erhartič)

Figure 6: Septarian concretions (Moeraki, New Zealand) are a rare form of geological and geomorphological natural heritage. They were also found in Slovenia (Šentilj) and destroyed during motorway construction (B. Erhartič)

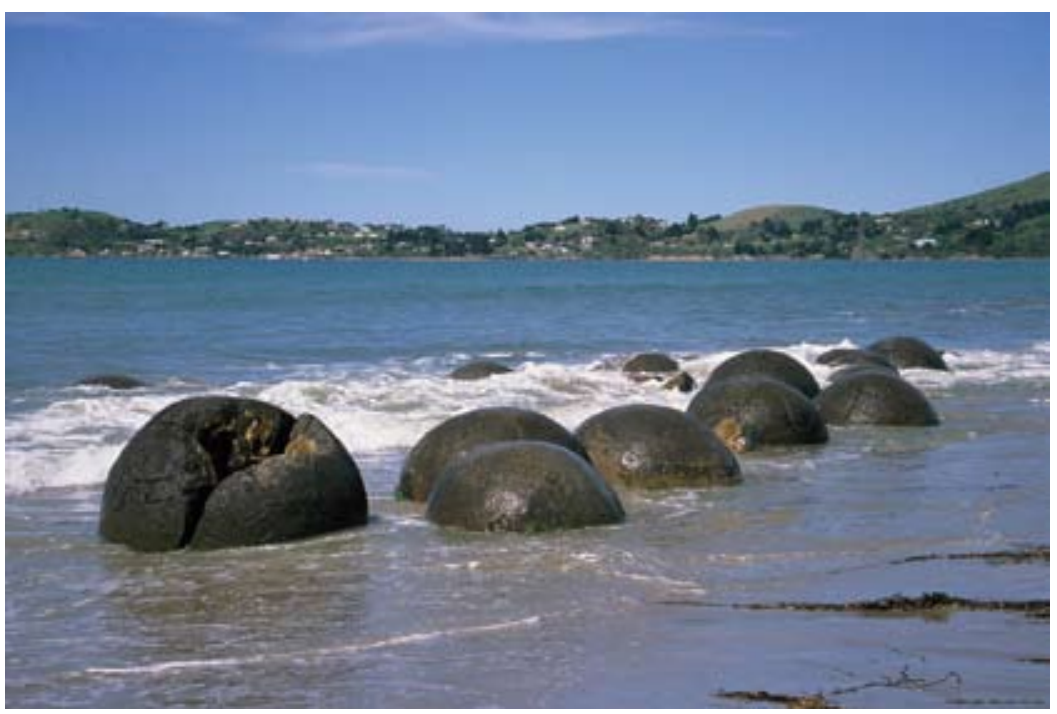

Med fizičnimi dejavniki, ki vplivajo na biodiverziteto sta najpomembnejša nadmorska višina in ekspozicija (primer različnega rastja na prisojnih in osojnih pobočjih Šmarne gore). Če razumemo in upoštevamo topografijo in orografijo ter geografsko širino, razporeditev morja in kopnega, dobimo neskončno veliko informacij o fizičnem okolju, ki daje ne le podlago, ampak tudi ključno vpliva na razvoj biodiverzitete.

Izjemna pestrost življenja na Zemlji se je tekom evolucije prilagodila fizičnemu okolju. Zato ima ta raznolik (geo)sistem funkcionalno vrednost za biološke sisteme in biodiverziteto. Postaja jasno, da velika geodiverziteta praviloma vodi do velike biodiverzitete (Gray 2004, 126).

\subsection{Znanstvenoraziskovalne in izobraževalne vrednote}

Študij geoloških skladov je razkril več milijard staro zgodovino Zemlje, zato lahko brez dvoma trdimo, da imajo plasti ogromno raziskovalno vrednost. Pojavila se je potreba po ohranjanju geoloških in geomorfoloških »zapisov« za izobraževanje in za prihodnje raziskave. Samo ohranjanje seveda ni dovolj, ključna je ustrezna interpretacija geodiverzitete.

Tovrstne raziskave in izobraževanje utegnejo postati v času podnebnih sprememb in večje pogostosti ekstremnih vremenskih stanj še bolj aktualne in pomembne. S proučevanjem 
dinamike naravnih sistemov, kot so na primer reke in obale, bomo morda lahko napovedali, kako bodo procesi na kopnem in na obali učinkovali v prihodnosti. Raziskave bodo v pomoč napovedovanju poplav in upravljanju - zaščiti pred njimi. Za poznavanje vplivov dviga morske gladine je bistveno razumevanje recentnih obalnih procesov.

Uničevanje naravnih fizikalnih sistemov in reliefnih oblik neizogibno zmanjšuje našo sposobnost raziskovanja (in izobraževanja) abiotskih sestavin okolja ter posledično slabšega poznavanja prihodnjih razmer in z njimi povezanega prilagajanja.

Prihodnje raziskave lahko pomagajo razrešiti sedanje globalne probleme, podpirati nove teorije in razvijati inovativne tehnike ali ideje, vendar le, če se bo ta geodiverziteta ohranila.

Določene lokacije lahko imajo tudi zgodovinsko-raziskovalno vrednost, saj je bil tam nek pojav, reliefna oblika prvič opisana, kot na primer v Sloveniji na kraškem svetu.

Slika 7: Balvan pri Mojstrani. Geomorfološka dediščina znanstvenoraziskovalnega, izobraževalnega in estetskega pomena (B. Erhartič)

Figure 7: Boulder near Mojstrana. Geomorphological value of research, educational and aesthetic significance (B. Erhartič)

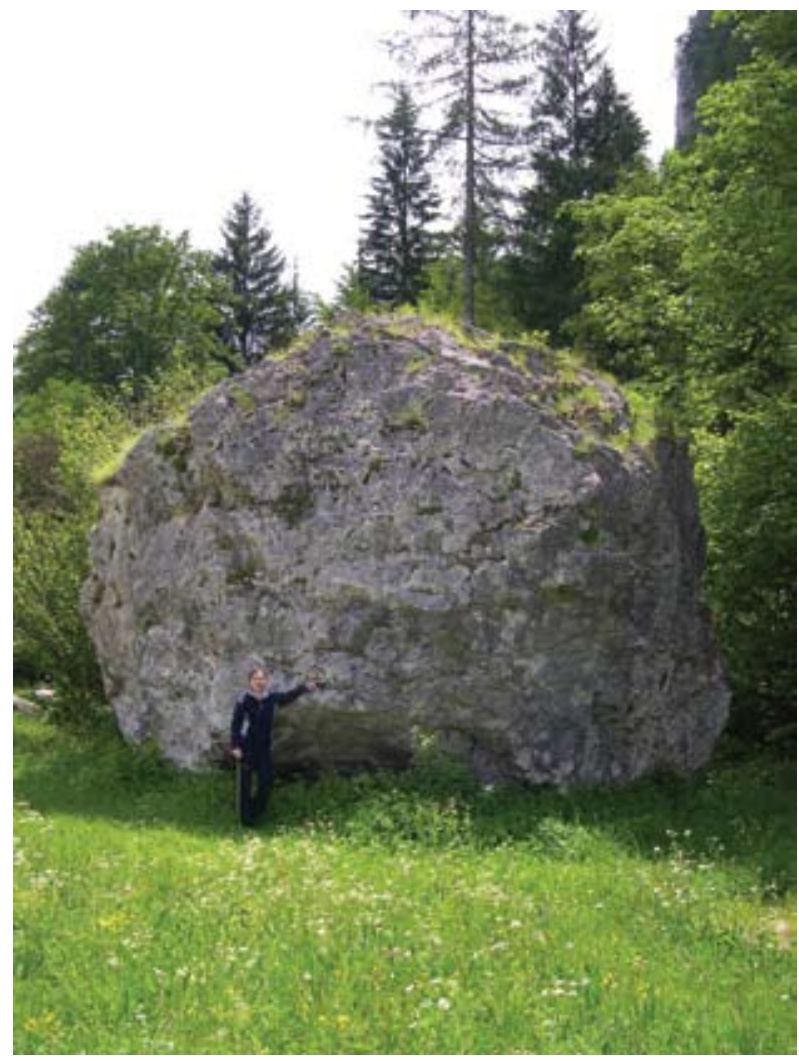


Zapisi v sedimentu, pa naj gre za jezera, šotišča, jamske sedimente ali led(enike) nosijo v sebi zapis preteklosti, bodisi za naravne procese ali za človekove aktivnosti, ki so vplivale na okolje. Podatki niso dragoceni samo za rekonstrukcijo preteklosti - preteklih vplivov človeka na okolje in rabe tal, temveč tudi za ocenjevanje sedanjih in prihodnjih dogajanj.

\section{SKLEP}

Reliefne oblike so ena najbolj razširjenih, takoj opaznih in atraktivnih naravnih neživih sestavin pokrajine. Naj gre za gorski greben, sotesko, naravni most ali klif, vedno so v človeku vzpodbudili zanimanje zaradi svojega privlačnega videza. Estetski vidik pa ni edini atribut, po katerem označimo poljubni pokrajinski element (reliefno obliko) kot pomemben - kot naravno vrednoto. Za vrednotenje je enako pomemben celoten niz vrednot: kulturnih, znanstvenih, izobraževalnih, socialno-ekonomskih ter intrinzičnih. Atributi so tisti, ki podajajo vrednost, ki omogočajo reliefni obliki, da jo označimo kot geomorfološko naravno vrednoto. $\mathrm{V}$ prihodnje bo potrebno veliko pozornosti nameniti kombiniranim vrednotam, saj so le-te zelo kompleksne, a tudi občutljive na posege in dejavnosti. Vrednosti se namreč lahko dopolnjujejo, prekrivajo - npr. estetska in ekonomska v smislu (geo)turizma, ali si nasprotujejo, so v konfliktu; npr. estetska in ekonomska $\mathrm{v}$ smislu izkoriščanja gradbenega kamna, pridobivanja energije.

Lahko zaključimo, da nas geodiverziteta spremlja in obdaja na vsakem koraku. Iz nje smo nastali, z njo smo neločljivo povezani, od nje smo odvisni. Zaradi naraščajočega števila in potreb prebivalstva prihaja do navzkrižja interesov in do prekomerne rabe geodiverzitete. Pojavlja se potreba po vzpostavitvi sistema geodiverzitete, tako na globalni ravni kot v Sloveniji, predvsem pa vrednotenja le-te. Vsega seveda ne moremo varovati; to niti ni smiselno in tega nočemo. Treba pa bo določiti, izpostaviti ter ovrednotiti najvrednejše dele nežive narave in zanje skrbeti, jih ohranjati ter ustrezno tržiti.

Ker ima geografija kot znanost najširši pogled na prostor, bi se morala aktivneje vključiti v kompleksen in multidisciplinaren sistem varstva narave, predvsem v proučevanje in ohranjanje njenih neživih komponent, torej geodiverzitete. Posebej kaže izpostaviti velik pomen geomorfologije pri določanju atributov, zlasti znanstvenoraziskovalnih. Geomorfološki pristop mora temeljiti na strokovnem znanju in vedenju o naravnih procesih, na poznavanju ustrezne zakonodaje in ozaveščanju pomembnosti geomorfoloških naravnih vrednot za človeštvo. Na trnovi poti ohranjanja narave se morata geografija in geomorfologija udejstvovati na vseh področjih uspešnega varstva, ki zajema odkrivanje in vrednotenje geodiverzitete, zakonske podlage, upravljanje in ne nazadnje - izobraževanje, ozaveščanje in interpretacijo pestrosti nežive narave.

\section{Viri in literatura}

Gray, M. 2004: Geodiversity, valuing and conserving abiotic nature. Department of Geography, Queen Mary, University of London. London. 
Guthrie, M. 2004: The social and economic value of geodiversity. Medmrežje: http://www. geoconservation.com/EHWH/Conference/presentations/guthrie.htm (30. 5. 2007).

Kirn, A. 2004: Narava-družba-ekološka zavest. Fakulteta za družbene vede. Ljubljana.

Medmrežje: http://www.ahc.gov.au/publications/anhc/parta.html\# (8. 8. 2007).

Panizza, M. 2003: Karst landforms as geomophosites. Dela 20. Ljubljana.

Sacks, J. 2002: The Dignity of Difference. London.

Skoberne, P. 2006: Blejsko jezero - portret Slovenije. Medmrežje: http://www.kam.si/izleti/ blejsko_jezero_portret_slovenije.html (10.8. 2007)

Stanley, M. 2002: Geodiversity, linking people, landscapes and their culture. Dublin.

Uredba o zvrsteh naravnih vrednot, Uradni list Republike Slovenije 52/2002 in 67/2003. Ljubljana.

Uredba o spremembah in dopolnitvah uredbe o zvrsteh naravnih vrednot, Uradni list Republike Slovenije 67/2003. Ljubljana.

Winkler, I. 2006: Vrednotenje naravne dediščine. Interno gradivo za študente Varstva naravne dediščine. Ljubljana.

Zakon o ohranjanju narave, Uradni list Republike Slovenija 96/2004. Ljubljana.

\section{LANDFORMS AS GEODIVERSITY (GEOMORPHOLOGICAL NATURAL HERITAGE)}

\section{Summary}

It is believed that we should not only tolerate difference but also celebrate it. The trend towards the value of diversity has nowhere been more evident than in the field of biology. In recent decades, the growing concern about species extinction and the loss of habitats has led to some important international environmental agreements. Although geological and geomorphological conservation has been practised for hundreds of years, most nature conservation organizations are still orientated mostly towards wildlife and biodiversity issues.

Geologists and geomorphologists started using the term geodiversity in the 1990s to describe the variety within abiotic nature. Geodiversity is seen as the diverse and complex connection of geological, geomorphological and soil features and processes in a defined area.

Slovenian Nature Conservation Act does not mention geodiversity but it defines some elements of nature that fit the term. According to the act valuable natural features are geological phenomena; minerals and fossils and mineral and fossil sites; surface and subsurface karst features; caves; gorges and other geomorphological phenomena; glaciers and glacial forms; springs; waterfalls; rapids; lakes; bogs; brooks and rivers with banks; seashore; ecosystems; landscape; and designed landscape. Slovenian legislation defines 10 different kinds of valuable natural features, at least four of them correspond to the term geodiversity: surface geomorphological, underground geomorphological, geological and hydrological valuable natural features. However, other types of valuable natural features may contain geodiversity as well. 
It does not make sense to protect all diversity of abiotic nature, but we have to value and protect the most valuable parts of it. Thus a discussion of the specific types of value is needed.

The article addresses the problem of evaluating geodiversity. Values of (valuable) natural features can be classified into intrinsic, cultural, aesthetic, socio-economic, functional, geosystem, research and educational ones.

Intrinsic values refer to the ethical belief that some things (e.g. the geodiversity of nature) are of value simply for what they are rather than what they can be used for by humans (utilitarian value). This is the most difficult value to describe since it involves ethical and philosophical dimensions of the relationship between society and nature. Geodiversity is an intrinsic value in the same way as biodiversity, but it also has other values.

The examples of cultural values of geodiverstity can be found around the world in forms of mythological explanations of landforms, archaeological sites, historical places and spiritual values. Many societies feel a strong bond with their physical surroundings and value these ties for cultural, as well as economic reasons.

The aesthetic values of geodiversity refer simply to the visual appeal (and that of other senses) provided by the physical environment. This may be through landforms at all scales from mountain ranges to small boulders which all have a certain value because of the diversity of topography they provide for local people or travellers. Landforms are undoubtedly undervalued as an element of landscape since there is a number of recreational activities (e.g. skiing, climbing etc.) that require specific landscapes.

Economists have attempted to put a financial value on all environmental assets, but many geological materials have more than a theoretical economic value. Economic mineral resources are usually classified into mineral fuels, specific minerals and construction stones, but the economic value of the abiotic environment should also include soil and other values and resources. Valuating natural heritage is problematic because it cannot be treated as market goods. Still it has its own price since it can be valued regarding to the benefits that it provides. We can use a WTP (willingness to pay) approach - how much money an individual is willing to pay for natural heritage.

Functional value has rarely been discussed in nature conservation, but it is clear that soils, landforms and rocks all have a functional role in environmental systems. Geodiversity has a functional value in providing the essential substrates and abiotic processes, which maintain physical and ecological systems at the Earth`s surface and thus underpin biodiversity. The land surface also provides a platform for all human activities. A combination of landforms, bedrock types or soils make some areas best suited for agriculture, others for tourism. Geodiversity therefore results in a diversity of utilitarian functional values of different parts of the landscape.

The physical environment generally plays a huge role in providing diverse environments, habitats and substrates that create biodiversity. Engineers and ecologists are more and more aware of the need to understand the processes and patterns in the physical environment if they are to manage processes and habitats successfully. Among physical (geo)factors that influence biodiversity, altitude and aspects rate as two most important. The physical environment is a laboratory for future research and is often the only field site which can provide a reliable test 
of many geological and geomorphological theories. We need to conserve some landforms (geomorphosites) for research and education purposes. By studying the dynamics of abiotic natural systems, such as rivers, glaciers, coasts etc., we may be able to predict how land and coastal processes will operate in the future.

The increase of public interest in geodiversity demands the redefinition of some concepts as well as an inventory and reevaluation of existing methodology. Only in this way we will be able to point out the most valuable features of geodiversity, market them in appropriate way and conserve them for the future. 